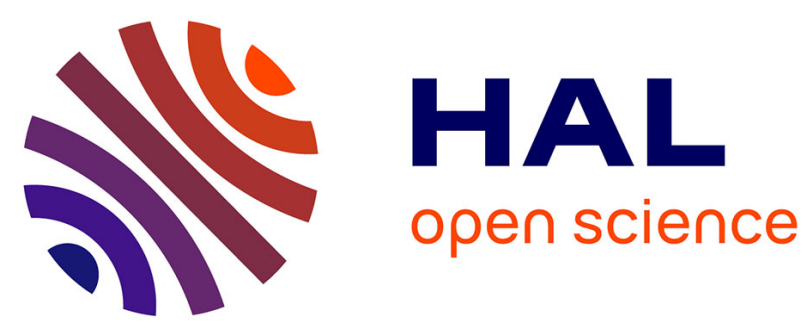

\title{
Responsiveness to intravenous immunoglobulins and occurrence of coronary artery abnormalities in a single-center cohort of Italian patients with Kawasaki syndrome
}

Donato Rigante, Piero Valentini, Daniela Rizzo, Andrea Leo, Gabriella Rosa, Roberta Onesimo, Alessia Nisco, Donatella Francesca Angelone, Adele Compagnone, Angelica Bibiana Delogu

\section{- To cite this version:}

Donato Rigante, Piero Valentini, Daniela Rizzo, Andrea Leo, Gabriella Rosa, et al.. Responsiveness to intravenous immunoglobulins and occurrence of coronary artery abnormalities in a single-center cohort of Italian patients with Kawasaki syndrome. Rheumatology International, 2010, 30 (6), pp.841-846. 10.1007/s00296-009-1337-1 . hal-00568324

\section{HAL Id: hal-00568324 https://hal.science/hal-00568324}

Submitted on 23 Feb 2011

HAL is a multi-disciplinary open access archive for the deposit and dissemination of scientific research documents, whether they are published or not. The documents may come from teaching and research institutions in France or abroad, or from public or private research centers.
L'archive ouverte pluridisciplinaire HAL, est destinée au dépôt et à la diffusion de documents scientifiques de niveau recherche, publiés ou non, émanant des établissements d'enseignement et de recherche français ou étrangers, des laboratoires publics ou privés. 


\section{Responsiveness to intravenous immunoglobulins and occurrence of coronary artery abnormalities in a single-centre cohort of Italian patients with Kawasaki syndrome}

Donato Rigante • Piero Valentini • Daniela Rizzo • Andrea Leo • Gabriella De Rosa •

Roberta Onesimo • Alessia De Nisco • Donatella Francesca Angelone • Adele Compagnone

- Angelica Bibiana Delogu

D. Rigante $(\bowtie) \cdot$ P. Valentini · D. Rizzo $\cdot$ R. Onesimo · D.F. Angelone · A. Compagnone

Department of Pediatric Sciences, Università Cattolica Sacro Cuore, Largo A. Gemelli, 8 I-00168 Rome, Italy

e-mail drigante@gmail.com

A. Leo

Department of Cardiology, Università Cattolica Sacro Cuore, Largo A. Gemelli, 8 I-00168 Rome, Italy

G. De Rosa · A. De Nisco - A.B. Delogu

Section of Pediatric Cardiology, Università Cattolica Sacro Cuore, Largo A. Gemelli, 8 I-00168 Rome, Italy 
Abstract Clues to predict the response to intravenous immunoglobulins (IVIG) and the development of coronary artery abnormalities (CAA) in children with Kawasaki syndrome (KS) are still undefined. We examined retrospectively the medical charts of children hospitalized between February 1990 and April 2009 with diagnosis of KS. A total of 32 Italian patients with a mean age of 23.8 months were analyzed and all received IVIG according to 2 schemes: 0.4 $\mathrm{g} / \mathrm{kg} /$ day for 5 days or $2 \mathrm{~g} / \mathrm{kg}$ in a single infusion, combined with oral acetylsalicylic acid. General, clinical and laboratory data were registered. Each patient was evaluated with echocardiography at admission, then with three-day and weekly frequency respectively during hospital stay and for the first 6-8 weeks since onset, and finally with a regular 6-12 month follow-up over time, according to patient risk stratification. Five patients showing significantly higher values of C-reactive protein at admission were IVIG-resistant after the first infusion ( $p=0.04$ ) in comparison with the remaining 27. Five patients out of 32 developed CAA, with no statistical significance when analyzed for IVIG dosage or IVIG-resistance. The demonstration of CAA was significantly higher in children aged less than 12 months $(p=0.037)$. Our experience, limited to a single-centre cohort of 32 patients with KS, though treated with 2 different IVIG schemes, has shown that higher values of C-reactive protein and younger age at onset are nodal points in determining respectively a failure in the response to IVIG and an increased occurrence of CAA.

Key-words: Kawasaki syndrome, intravenous immunoglobulins, coronary artery abnormalities 


\section{Introduction}

More than 40 years after the original description by the Japanese pediatrician Tomisaku Kawasaki about the clinical signs of Kawasaki syndrome (KS) we are still unable to define its etiology, understand the nature of endothelial damage, predict the responsiveness to treatment or the risk of its vascular complications. Although initially recognized as benign, this syndrome was subsequently acknowledged to have serious cardiovascular concerns, gaining the worldwide interest of pediatricians and pediatric cardiologists [1,2]: nowadays $\mathrm{KS}$ is the most common cause of acquired pediatric heart disease in the developed world $[3,4]$.

Diagnosis of KS requires that fever persisting for 5 days or more is accompanied by at least 4 of the following 5 clinical signs: polymorphous rash, bilateral conjunctival congestion, oral mucosal changes, non-purulent cervical lymphadenitis, abnormalities in the peripheral extremities and perineum [5]. High-dose intravenous immunoglobulins (IVIG) are the most effective treatment to reduce KS acute symptoms and prevent the occurrence of coronary artery abnormalities (CAA), which develop in 15 to $25 \%$ of untreated children and even in 5-10\% of children adequately treated [6]. However, 5$15 \%$ of patients with KS do not respond to IVIG and this category shows the highest risk of developing CAA or even ischemic heart disease [7].

Attempting to identify which patients should be unresponsive to treatment or predicting the ones who might display a significant risk of developing cardiologic sequelae are two issues of outstanding priority, still unresolved in the medical literature. Aim of our evaluation was to study retrospectively a cohort of Italian patients with diagnosis of KS, hospitalized in a single-centre during a period of 18 years, and analyze their general, clinical and laboratory data as possible predictors for resistance to IVIG and for CAA occurrence.

\section{Cohort of patients, methods and statistical evaluation}


A retrospective review of patients' medical charts was carried out for all children admitted to our Department between February 1990 and April 2009 and discharged from hospital with diagnosis of KS. Each chart was examined by both a pediatrician and a pediatric cardiologist. A written informed consent was obtained by each family. Exclusion criteria for our evaluation included prior treatment with IVIG or systemic steroids, presence of another disease known to mimic KS, previous diagnosis of $\mathrm{KS}$ and the presence of contraindications to IVIG or acetylsalicylic acid (aspirin). Atypical forms of KS were excluded by our study.

Thirty-two Italian children were considered in our evaluation. For each patient the following data were collected: age, sex, clinical signs and all laboratory data at diagnosis, illness days before IVIG, IVIG dose, eventual IVIG additional dose, CAA at the time of diagnosis or over follow-up. Illness day 1 was defined as the first day of fever. Unresponsiveness to IVIG was defined as persistent fever $\left(\geq 37.5^{\circ} \mathrm{C}\right)$ over 24 hours after the first IVIG infusion [8]. For nonresponder patients one supplementary dose of IVIG was administered. Cardiologic evaluation and serial echocardiograms were performed at KS recognition after hospital admission, then with 3-day frequency during hospitalization and with weekly frequency over the first 6-8 weeks. After discharge periodic cardiologic evaluations were performed according to each patient's risk stratification at intervals of 6-12 months.

Normality of distribution was assessed through the use of the KolmogorovSmirnov test. Categorical data were compared using Fisher's exact test. Continues variables, normally distributed, were analysed using Student's $t$-test. Data that were not normally distributed were compared by using the Mann-Whitney $U$ test. $P$-values $\leq 0.05$ were considered statistically significant. All tests were two-tailed and the statistical analysis was performed with the Statistical Package for Social Sciences (SPSS) 11.0 program for Windows (Chicago, Illinois).

\section{Results}


Thirty-two patients included in our analysis (20 males and 12 females, male/female ratio: 1.7/1) had a mean age of 23.8 months and were of Italian ancestry. Median age at diagnosis was 17,5 months, ranging from 2.3 to 80.2 months. All patients had fever (ranging from 38.2 to $40.1^{\circ} \mathrm{C}$ ) and its median duration was 7 days (range 5-18 days). IVIG were administered to all patients: 10 children, treated before 1999, received $400 \mathrm{mg} / \mathrm{kg} /$ day for 5 days and 22 children, treated after 1999, received $2 \mathrm{~g} / \mathrm{kg}$ in a single 12 hour-infusion. IVIG were given at a variable time since disease onset and were associated with oral high-dose aspirin (50-100 mg/kg/day) during the acute phase, followed by low-dose aspirin (3-5 $\mathrm{mg} / \mathrm{kg} /$ day) for a variable period, depending on the echocardiographic results. None of patients who had recovered completely from the original episode had a recurrent disease.

Five patients (15.6\%) out of the initial cohort were IVIG-resistant and the remaining 27 responded completely to the first IVIG infusion. Table 1 shows the comparison between the groups of IVIG-responders and nonresponders as for general and laboratory data. Table 2 lists the distribution of KS clinical signs between IVIGresponder and nonresponder groups. There was no statistically significant difference in age, sex, clinical signs and laboratory results between the two groups. Nonresponders were diagnosed and treated in a most precocious time when compared with responders: the median day of illness at which IVIG were infused in nonresponders was earlier than in responders (5 vs 7 days, $p=0.08$ ); in addition, the nonresponder group showed significantly higher $\mathrm{C}$-reactive protein (CRP) in comparison with responders $(p=0.04)$.

Five $(15.6 \%)$ out of the 32 patients developed CAA, defined as coronary dilations more than 2 standard deviations (SD) higher than the expected mean, after body surface area adjustment. Ten patients with no apparent involvement of coronary arteries presented an endothelial brightness at a qualitative echocardiographic assessment. The proportion of CAA in IVIG-nonresponders was higher than in responders, though with no statistical significance (20\% [1/5] vs $14.8 \%$ [4/27], $p=1)$. In particular, 6 patients had an incomplete form of KS and 2 of them displayed CAA.

Ten children treated before 1999 received IVIG at the dose of $400 \mathrm{mg} / \mathrm{kg} / \mathrm{day}$ for 5 consecutive days, according to the clinical practice of that period: we observed a 
higher percentage of IVIG-nonresponders in this group than in the 22 children treated with a single IVIG infusion of $2 \mathrm{~g} / \mathrm{kg}$ after 1999, though with no statistical significance $(20 \%$ [2/10] vs $13.6 \%$ [3/22], $p=1)$. Although there was a trend for patients in the first group to have more CAA than those in the second one (respectively $30 \%$ [3/10] vs $9 \%$ $[2 / 22])$, this difference was not statistically significant $(p=0.30)$, maybe due to the limited number of patients. In addition, patients with CAA had higher levels of white blood cell count at diagnosis in comparison with those without CAA $\left(23.70 \times 10^{9} / 1 \mathrm{vs}\right.$ $\left.16.05 \times 10^{9} / 1, p=0.01\right)$. At a long-term follow-up all CAA resolved completely in all patients, even in the youngest patient, who had an incomplete clinical presentation.

Eleven patients (34.4\%, 6 males and 5 females) out of the cohort were less than 1 year old: $2(18.2 \%)$ of this 11 children were IVIG-nonresponders in comparison with $3 / 21$ nonresponder aged more than 1 year $(14.3 \%)$ with no statistical significance $(p=1)$. The incidence of CAA was significantly higher in the group of less than 1-year-old children in comparison with the group of children over 1 year $(36.4 \%$ [4/11] vs $4.8 \%$ [1/21], $p=0.037$ ). Table 3 shows the comparison of general and laboratory data with regard to the occurrence of CAA. Figure 1 shows the relationship between age at diagnosis and occurrence of CAA.

\section{Discussion}

Many clinicians have been making outstanding efforts to uncover the mysteries behind KS, though the definition of its outcome remains hazy, even for cases with echocardiographically normal coronary arteries. Even if KS remains a self-limited panvasculitis involving small and medium-sized muscular arteries in children of all ethnic backgrounds, the disease bears an intrinsic risk of severe cardiovascular sequelae: a continuous spectrum ranging from no apparent involvement in the majority of patients to the presence of multiple giant aneurysms is recognized [9]. The primary end-point of treatment in KS is the prevention of any vascular injuries and the risk of developing CAA is clearly decreased by IVIG administration during the acute phase [10]. In the last decade a single high-dose IVIG infusion ( $2 \mathrm{~g} / \mathrm{kg}$ of body weight) has been considered the gold-standard treatment for KS [11]. 
It is widely known that more than $10 \%$ of $\mathrm{KS}$ patients fail to defervesce with initial IVIG treatment [12]. Egami et al showed that resistance to IVIG treatment can be predicted evaluating age, illness days, platelet count, serum transaminase level and CRP [13]. A multivariate analysis by Sano et al in 112 patients with KS, who received IVIG within 2 days, selected high CRP, total bilirubin and aspartate aminotransferase as independent predictors of low rate of response to initial IVIG treatment, finding that patients with at least two increased predictors of the three might result unresponsive to IVIG [14]. Failure of a single IVIG dose might occur in up to $11.6 \%$ of KS patients, especially if displaying low hemoglobin, high neutrophil count and low albumin [15]. In the most recent medical literature it has been accepted that an anticipated identification of IVIG-nonresponders might decrease the overall incidence of CAA through a "most intense" treatment and that the main predictor of CAA occurrence is the overall duration of fever longer than 8 days [16].

In our evaluation 32 Italian patients with KS had a median duration of fever of 7 days: $15.6 \%$ of them were nonresponders to the initial IVIG infusion, receiving a second IVIG dose which led to disease remission, and the same percentage (15.6\% of the cohort) developed CAA. There was no statistically significant difference for children treated with the two IVIG regimens both for the percentage of nonresponders and the occurrence of CAA. In addition, sex ratio in the nonresponder group showed that males were more represented than females (4 males to 1 female). IVIG-responders had a lower CRP $(p=0.04)$ and showed a tendency to a longer duration of fever before IVIG infusion, when compared with the nonresponder group. The overall "amount of inflammation" resulted critical both for response to therapy and for development of CAA, as demonstrated by higher CRP levels in nonresponders and white blood cell count in patients with CAA. As observed in previous studies, we have found a higher incidence of CAA in IVIG-nonresponders compared to responders (20\% vs $14.8 \%$ ), though without statistical significance: this might be explained by the small sample studied, including incomplete forms and cases treated beyond 10 days of fever. However, children with less than 1 year have developed CAA in a higher statistically significant percentage if compared with children over 1 year of age $(36.4 \%$ vs $4.8 \%$, 
$p=0.037$ ). This observation has been confirmed by studies of surveillance in larger groups of patients with KS from Japan, Korea and Taiwan [17-19]. Possible genetic variants in the major histocompatibility complex region that are associated with $\mathrm{KS}$ might influence the responsiveness to IVIG and the development of CAA [20,21]. Limitations of the present report are common to most retrospective studies, though we want to underline the small number of patients, all deriving from a single-centre, and the administration of two different IVIG schemes.

It is known that at least transient CAA might develop in approximately 5-10\% and giant aneurysms in $1 \%$ of children with $\mathrm{KS}$ despite prompt treatment with IVIG: these ones must be given within 7 to 10 days to be most effective in preventing the development of CAA. In addition, very young infants, especially those exhibiting an incomplete clinical KS presentation, have the highest rate of CAA and for this reason echocardiography should be performed on any infant younger than age 6 months with fever duration exceeding 7 days, increased CRP or no other explanation for the febrile illness [22]. The relationship between the duration of illness before treatment and the frequency of occurrence of CAA was examined by Baer et al, who emphasized the relevance of the initial echocardiography as an adjunctive diagnostic test especially for incomplete forms of KS [23].

Coronary artery assessment by echocardiography needs to quantify internal coronary artery diameters: commonly used definitions have relied on the Japanese Ministry of Health criteria, which arbitrarily defined CAA as a maximum absolute internal diameter superior than $3 \mathrm{~mm}$ in children aged less than 5 years or superior than $4 \mathrm{~mm}$ in children aged more than 5 years [24,25]. In 1998 de Zorzi et al reported that internal diameters of coronary arteries of $\mathrm{KS}$ patients adjusted for their body surface area, as $z$-scores calculated using a non-linear regression model, were significantly larger than normal non-febrile controls and that $27 \%$ of patients classified as having "normal" coronary arteries according to the Japanese Research Committee criteria would have had at least one coronary abnormality by their new criteria [26]. An increase in CAA recognition has been attributed to the widespread use of de Zorzi's criteria, which led to the discovery of larger body surface area-adjusted dimensions of 
coronary arteries in all phases of KS. Newer data are delineating vascular abnormalities as perivascular echogenicity or brightness, luminal irregularities and abnormal vessel tapering of the coronary arteries even in those KS patients in whom CAA were never detected and endothelial dysfunction is believed to be crucial to the pathogenesis of coronary vasoconstriction and myocardial ischemia [27,28]. During KS acute phase we observed a perivascular endothelial brightness of coronary arteries in 10 out of 32 patients, which did not evolve to any dilations: we used de Zorzi's criteria to measure at baseline left main and proximal right coronary artery dimensions in centimetres (normal values do not exist for distal segments of the circumflex artery), considering body surface area for each patient, and finding that 2/5 children having CAA did not meet the 1984 Japanese Ministry of Health criteria. In all our patients we observed the echocardiographic resolution of CAA, in accordance with a host of literature data related to large numbers of patients confirming that coronary ectasia or small coronary aneurysms have a good prognosis and a greater chance to undergo total regression.

In consideration of the overall risk of long-term cardiac sequelae, combined with the risk of a premature accelerated atherosclerosis and its consequences, we strongly believe that multicenter randomized clinical trials are needed to establish the best strategy to manage high-risk patients with $\mathrm{KS}$, i.e. the youngest ones, by stricter monitoring or eventual administration of additional antinflammatory therapies, though the optimal surveillance modalities are still far to be unraveled especially for low-risk patients.

\section{References}

1. Kawasaki T (1967) Acute febrile mucocutaneous syndrome with lymphoid involvement with specific desquamation of the fingers and toes in children. Arerugi 16:178-222.

2. Burns JC (2002) Commentary: translation of Dr. Tomisaku Kawasaki's original report of fifty patients in 1967. Pediatr Infect Dis J 21:993-1005.

3. Burns JC (2004) Kawasaki syndrome. Lancet 364:533-544.

4. Holman RC, Curns AT, Belay ED, Steiner CA, Schonberger LB (2003) Kawasaki syndrome hospitalizations in the United States, 1997 and 2000. Pediatrics 112:495-501.

5. Ozen S, Ruperto N, Dillon MJ, Bagga A, Barron K, Davin JC, Kawasaki T, Lindsley C, Petty RE, Prieur AM, Ravelli A, Woo P (2006) EULAR/PReS endorsed consensus criteria for the classification of childhood vasculitides. Ann Rheum Dis 65;936-941. 
6. Satou GM, Giamelli J, Gewitz MH (2007) Kawasaki disease: diagnosis, management and longterm implications. Cardiol Rev 15:163-169.

7. Dajani AS, Taubert KA, Takahashi M, Bierman FZ, Freed MD, Ferrieri P, Gerber M, Shulman ST, Karchmer AW, Wilson W (1994) Guidelines for long-term management of patients with Kawasaki disease: report from the Committee on rheumatic fever, endocarditis and Kawasaki disease, Council on cardiovascular disease in the young, American Heart Association. Circulation 89:916-922.

8. Kobayashi T, Inoue Y, Takeuchi K, Okada Y, Tamura K, Tomomasa T, Kobayashi T, Morikawa A (2006) Prediction of intravenous immunoglobulin unresponsiveness in patients with Kawasaki disease. Circulation 113:2606-2612.

9. De Rosa G, Pardeo M, Rigante D (2007) Current recommendations for the pharmacological therapy in Kawasaki syndrome and management of its cardiovascular complications. Eur Rev Med Pharmacol Sci 11:301-308.

10. Newburger JW, Takahashi M, Burns JC, Beiser AS, Chung KJ, Duffy CE, Glode MP, Mason WH, Reddy V, Sanders SP (1986) The treatment of Kawasaki syndrome with intravenous gamma globulin. N Engl J Med 315:341-347.

11. Newburger JW, Takahashi M, Beiser AS, Burns JC, Bastian J, Chung KJ, Colan SD, Duffy CE, Fulton DR, Glode MP (1991) A single intravenous infusion of gamma globulin as compared with four infusions in the treatment of acute Kawasaki syndrome. N Engl J Med 324:1633-1639.

12. Wallace CA, French JW, Kahn SJ, Sherry DD (2000) Initial intravenous gammaglobulin treatment failure in Kawasaki disease. Pediatrics 105:E78.

13. Egami K, Muta H, Ishii M, Suda K, Sugahara Y, Iemura M, Matsuishi T (2006) Prediction of resistance to intravenous immunoglobulin treatment in patients with Kawasaki disease. J Pediatr 149:237-240.

14. Sano T, Kurotobi S, Matsuzaki K, Yamamoto T, Maki I, Miki K, Kogaki S, Hara J (2007) Prediction of non-responsiveness to standard high-dose gamma-globulin therapy in patients with acute Kawasaki disease before starting initial treatment. Eur J Pediatr 166;131-137.

15. Durongpisitkul K, Soongswang J, Laohaprasitiporn D, Nana A, Prachuabmoh C, Kangkagate C (2003) Immunoglobulin failure and retreatment in Kawasaki disease. Pediatr Cardiol 24:145-148.

16. Kim T, Choi W, Woo CW, Choi B, Lee J, Lee K, Son C, Lee J (2007) Predictive risk factors for coronary artery abnormalities in Kawasaki disease. Eur J Pediatr 166;421-425.

17. Nakamura Y, Yashiro M, Uehara R, Oki I, Watanabe M, Yanagawa H (2008) Epidemiologic features of Kawasaki disease in Japan: results from the nationwide survey in 2005-2006. J Epidemiol 18:167-172.

18. Yeo Y, Kim T, Ha K, Jang G, Lee J, Lee K, Son C, Lee J (2009) Incomplete Kawasaki disease in patients younger than 1 year of age: a possible inherent risk factor. Eur J Pediatr 168:157-162.

19. Huang WC, Huang LM, Chang IS, Chang LY, Chiang BL, Chen PJ, Wu MH, Lue HC, Lee CY, Kawasaki Disease Research Group (2009) Epidemiologic features of Kawasaki disease in Taiwan, 2003-2006. Pediatrics 123:e401-405.

20. Kato S, Kimura M, Tsuji K, Kusakawa S, Asai T, Juji T, Kawasaki T (1978) HLA antigens in Kawasaki disease. Pediatrics 61:252-255.

21. Lin YJ, Wan L, Wu JY, Sheu JJ, Lin CW, Lan YC, Lai CH, Hung CH, Tsai Y, Tsai CH, Lin TH, Lin JG, Hsueh KC, Huang YM, Chang JS, Tsai FJ (2009) HLA-E gene polymorphism associated with susceptibility to Kawasaki disease and formation of coronary artery aneurysms. Arthritis Rheum 60:604-610.

22. Newburger JW, Takahashi M, Gerber MA, Gewitz MH, Tani LY, Burns JC, Shulman ST, Bolger AF, Ferrieri P, Baltimore RS, Wilson WR, Baddour LM, Levison ME, Pallasch TJ, Falace DA, Taubert KA; Committee on Rheumatic Fever, Endocarditis and Kawasaki Disease; Council on Cardiovascular Disease in the Young; American Heart Association; American Academy of Pediatrics (2004) Diagnosis, treatment, and long-term management of Kawasaki 
disease: a statement for health professionals from the Committee on Rheumatic Fever, Endocarditis and Kawasaki Disease, Council on Cardiovascular Disease in the Young, American Heart Association. Circulation 110:2747-2771.

23. Baer AZ, Rubin LG, Shapiro CA, Sood SK, Rajan S, Shapir Y, Romano A, Bierman FZ (2006) Prevalence of coronary artery lesions on the initial echocardiogram in Kawasaki syndrome. Arch Pediatr Adolesc Med 160:686-690.

24. Research Committee on Kawasaki disease (1984) Report of subcommittee on standardization of diagnostic criteria and reporting of coronary artery lesions in Kawasaki disease. Tokyo, Japan: Japanese Ministry of Health and Welfare.

25. Capannari TE, Daniels SR, Meyer RA, Schwartz DC, Kaplan S (1986) Sensitivity, specificity and predictive value of two-dimensional echocardiography in detecting coronary artery aneurysms in patients with Kawasaki disease. J Am Coll Cardiol 7:355-360.

26. de Zorzi A, Colan SD, Gauvreau K, Baker AL, Sundel RP, Newburger JW (1998) Coronary artery dimensions may be misclassified as normal in Kawasaki disease. J Pediatr 133:254-258.

27. McCrindle BW, Li JS, Minich LA, Colan SD, Atz AM, Takahashi M, Vetter VL, Gersony WM, Mitchell PD, Newburger JW (2007) Coronary artery involvement in children with Kawasaki disease. Risk factors from analysis of serial normalized measurements. Circulation 116:174-179.

28. Furuyama H, Odagawa Y, Katoh C, Iwado Y, Ito Y, Noriyasu K, Mabuchi M, Yoshinaga K, Kuge Y, Kobayashi, K, Tamaki N (2003) Altered myocardial flow reserve and endothelial function late after Kawasaki disease. J Pediatr 142:149-154. 
Table 1. Comparison of general and laboratory data in the IVIG-responder and IVIGnonresponder groups of patients with Kawasaki syndrome.

\begin{tabular}{|c|c|c|c|}
\hline & $\begin{array}{l}\text { IVIG- } \\
\text { responders } \\
(\mathrm{n}=27)\end{array}$ & $\begin{array}{c}\text { IVIG- } \\
\text { nonresponders } \\
(\mathrm{n}=5)\end{array}$ & $p$ \\
\hline $\operatorname{Sex}(\mathrm{M} / \mathrm{F})$ & $16 / 11$ & $4 / 1$ & $0,637 \square$ \\
\hline Median age in months (min-max) & $\begin{array}{c}16,77 \\
(4,07-80,23)\end{array}$ & $\begin{array}{c}23,07 \\
(2,3-36,73)\end{array}$ & $0,48^{*}$ \\
\hline Patients with less than 1 year, $\mathrm{n}(\%)$ & $9(33 \%)$ & $2(40 \%)$ & $1 \square$ \\
\hline Median day at IVIG infusion (min-max) & $7(4-18)$ & $5(5-11)$ & $0,08 \square$ \\
\hline $\begin{array}{l}\text { White blood cell count }\left(\times 10^{9} / 1\right) \text {, } \\
\text { median (min-max) }\end{array}$ & $16,5(9,74-38,61)$ & $13,2(6,47-24)$ & $0,22 *$ \\
\hline Neutrophil count $(\%)$, mean \pm SD & $69,32 \pm 13,9$ & $75 \pm 8,46$ & $0,40 \diamond$ \\
\hline C-reactive protein $(\mathrm{mg} / \mathrm{l})$, median (min-max) & $105(17,40-232)$ & $197,5(94-209)$ & $0,04^{*}$ \\
\hline Hemoglobin $(\mathrm{g} / \mathrm{dl})$, mean $\pm \mathrm{SD}$ & $10,84 \pm 1,02$ & $10,36 \pm 1,07$ & $0,34 \diamond$ \\
\hline Platelet count $\left(\times 10^{7} / 1\right)$, median (min-max) & $384(65-723)$ & $426(306-761)$ & $0,51^{*}$ \\
\hline Albumin (g/dl), mean \pm SD & $3,82 \pm 0,59$ & $3,58 \pm 0,311$ & $0,40 \diamond$ \\
\hline Sodium $(\mathrm{mEq} / \mathrm{l})$, mean $\pm \mathrm{SD}$ & $134,18 \pm 3,45$ & $132 \pm 2,55$ & $0,19 \diamond$ \\
\hline $\begin{array}{l}\text { Aspartate aminotransferase (IU/l), } \\
\text { median (min-max) }\end{array}$ & $35(11-654)$ & $45(23-101)$ & $0,80^{*}$ \\
\hline $\begin{array}{l}\text { Alanine aminotransferase (IU/l), } \\
\text { median (min-max) }\end{array}$ & $18(9-548)$ & $88(22-225)$ & $0,1^{*}$ \\
\hline
\end{tabular}


Table 2. Distribution of clinical signs in the acute phase of Kawasaki syndrome between IVIG- responder and IVIG-nonresponder groups.

\begin{tabular}{|l|c|c|c|}
\hline & $\begin{array}{c}\text { IVIG- } \\
\text { responders } \\
(\mathrm{n}=27)\end{array}$ & $\begin{array}{c}\text { IVIG- } \\
\text { nonresponders } \\
(\mathrm{n}=5)\end{array}$ & $\boldsymbol{p}^{\square}$ \\
\hline Sterile conjunctivitis, n (\%) & $22(81 \%)$ & $3(60 \%)$ & 0.30 \\
\hline Cervical lymph node enlargement, n (\%) & $19(70 \%)$ & $3(60 \%)$ & 0.64 \\
\hline Erythema of lips/oral cavity, n (\%) & $23(85 \%)$ & $5(100 \%)$ & 1 \\
\hline Abnormal extremities/perineum, n (\%) & $18(67 \%)$ & $3(60 \%)$ & 1 \\
\hline Polymorphous rash, n (\%) & $22(81 \%)$ & $5(100 \%)$ & 0.56 \\
\hline
\end{tabular}

$\square$ according to Fisher's exact test 
Table 3. Comparison of general and laboratory data in patients with Kawasaki syndrome with regard to the occurrence of coronary artery abnormalities.

\begin{tabular}{|l|c|c|c|}
\hline & $\begin{array}{r}\text { Patients } \\
\text { without } \\
\text { coronary } \\
\text { abnormalities } \\
(\mathrm{n}=27)\end{array}$ & $\begin{array}{c}\text { Patients with } \\
\text { coronary } \\
\text { abnormalities } \\
(\mathrm{n}=5)\end{array}$ & $\boldsymbol{p}$ \\
\hline Sex (M/F) & $19 / 8$ & $2 / 3$ & $0.31 \square$ \\
\hline Median age in months (min-max) & $21,3(3,3-80,23)$ & $6,9(2,30-48,23)$ & $0.06^{*}$ \\
\hline Patients with less than 1 year, n (\%) & $7(26 \%)$ & $4(80 \%)$ & $0.037 \square$ \\
\hline Median day at IVIG infusion (min-max) & $7(5-18)$ & $11(6-11)$ & $0.1^{*}$ \\
\hline $\begin{array}{l}\text { White blood cell count (x 10\%/l), } \\
\text { mean } \pm \text { SD }\end{array}$ & $16,05 \pm 4,67$ & $23,70 \pm 10,34$ & $0.01 \diamond$ \\
\hline Neutrophil count (\%), mean \pm SD & $70,19 \pm 13,88$ & $70,72 \pm 10,45$ & $0.94 \diamond$ \\
\hline $\begin{array}{l}\text { C-reactive protein (mg/l), median (min- } \\
\text { max) }\end{array}$ & 121,88 & $98,12(19-146)$ & $0.61^{*}$ \\
\hline Hemoglobin (g/dl), mean \pm SD & $10,77 \pm 0,98$ & $10,76 \pm 1,43$ & $0.98 \diamond$ \\
\hline Platelet count (x 10/l), median (min-max) & $384(173-761)$ & $415(65-486)$ & $0.80^{*}$ \\
\hline Albumin (g/dl), mean \pm SD & $3,77 \pm 0,54$ & $3,84 \pm 0,71$ & $0.8 \diamond$ \\
\hline Sodium (mEq/l), mean \pm SD & $133,78 \pm 3,36$ & $134,2 \pm 3,96$ & $0.80 \diamond$ \\
\hline $\begin{array}{l}\text { Aspartate aminotransferase (IU/l), } \\
\text { median (min-max) }\end{array}$ & $37(19-654)$ & $23(11-103)$ & $0.12^{*}$ \\
\hline $\begin{array}{l}\text { Alanine aminotransferase (IU/l), } \\
\text { median (min-max) }\end{array}$ & $40(9-548)$ & $17(11-115)$ & $0.24^{*}$ \\
\hline
\end{tabular}

\footnotetext{
* according to Mann-Whitney test

$\diamond$ according to Student's $t$-test

$\square$ according to Fisher's exact test
} 
Figure 1. Relationship between age (in months) at diagnosis of Kawasaki syndrome and occurrence of coronary artery abnormalities.

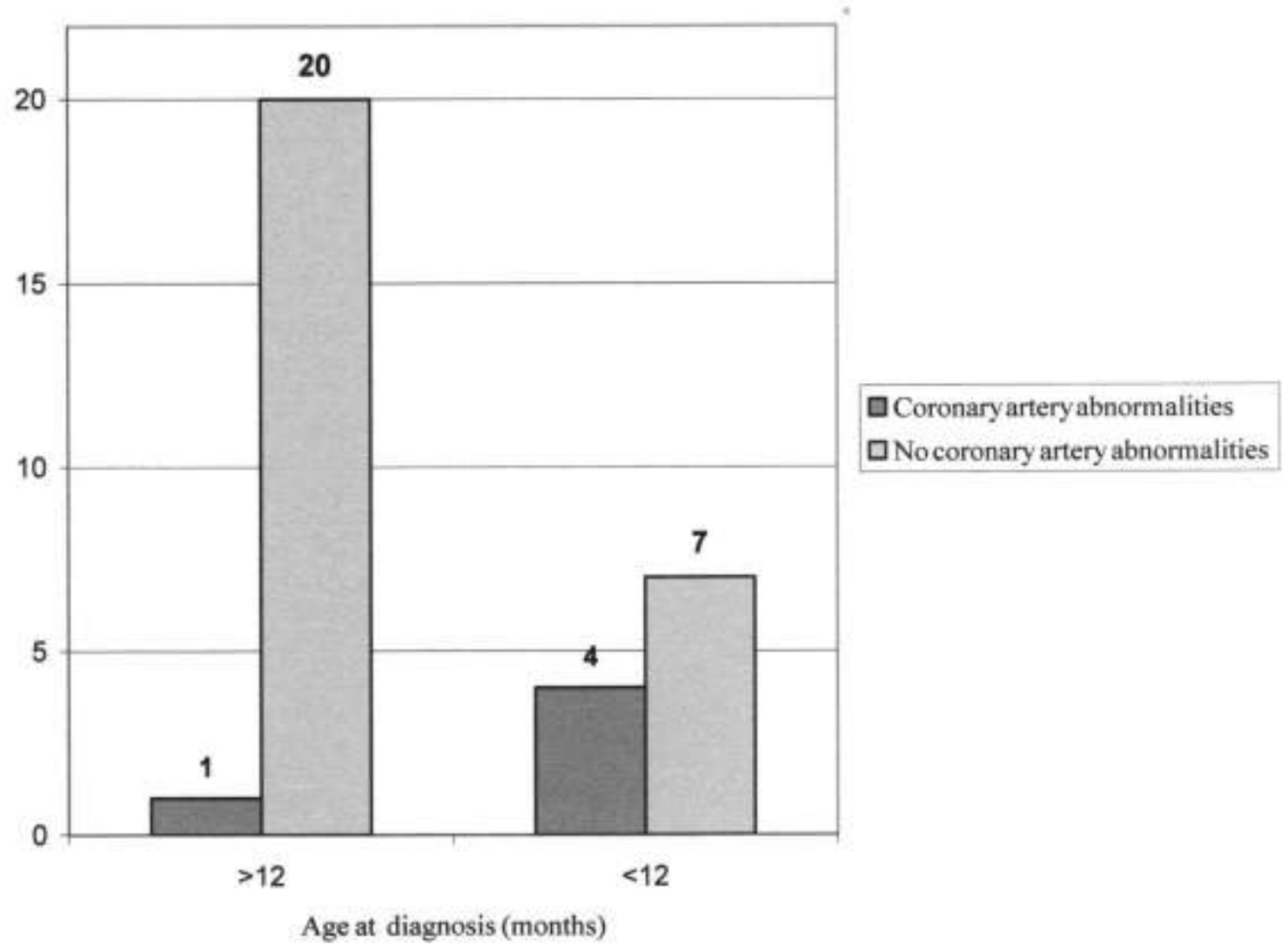

